\title{
MDM-BASED BUFFER ESTIMATION IN CONSTRUCTION PROJECTS
}

\author{
Rohan Singhal ${ }^{1}$, J. Uma Maheswari ${ }^{2}$, V. Paul C. Charlesraj ${ }^{3}$, and Aritra Pal ${ }^{4}$
}

\begin{abstract}
Schedule delay and cost overrun are the two major challenges for the successful project delivery in construction. It has been reported that significant delays in construction projects are caused by rework and there are several reasons for rework. A framework has been proposed to assess the delay due to two primary reasons for rework, (i.e. design changes and non-conformances), using Multiple Domain Matrix (MDM), a matrix-based technique. This methodology would help the project planners to create an as-adjusted schedule that is more appropriate compared to as-planned or as-built schedules. Further, it is possible to arrive at a meaningful estimate of activity buffer time in order to account for delays due to rework. Eventually, this would lead to successfully implement one of the key principles of lean, namely, elimination of time-related "waste" that is due to defect and/or delay.
\end{abstract}

\section{KEYWORDS}

Buffer, delay assessment, job-sequencing, multiple domain matrix, waste.

\section{INTRODUCTION}

Indian construction industry is growing in a rapid pace and the recent initiatives are accelerating the process of growth. In India, construction industry is contributing $8 \%$ of the country's gross domestic product (GDP) and the current growth rate of this sector is 8.1\%(Make in India 2018). Recent policies and investments are expected to bring a revolutionary change in the construction sector in the near future. Investments in urban infrastructure, 100\% Foreign Direct Investment (FDI), increased investment in smart cities and Atal Mission for Rejuvenation and Urban Transformation (AMRUT) city projects, Swachh Bharat Mission (SBM) are some of those initiatives(Make in India 2018).Although construction sector is growing rapidly, the challenges in successful project delivery still exist. The latest monthly flash report of Ministry of Statistics and Programme Implementation (MOSPI) shows an alarming condition of Infrastructure

Graduate Student, Indian Institute of Technology Delhi, New Delhi, India, rohanssinghal@gmail.com Assistant Professor, Indian Institute of Technology Delhi, New Delhi, India, umapaul@civil.iitd.ac.in Associate Professor, RICS School of Built Environment, Delhi NCR, India, vpcharlesraj@ricssbe.edu.in

4 Assistant Professor, RICS School of Built Environment, Mumbai, India, aritra.pal.1989@gmail.com 
projects in India. Out of 1,231 ongoing infrastructure projects costing `1500 million and above, about $27 \%$ of the projects are either facing cost overrun or delayed(MOSPI 2017). It is mainly due to rework at construction sites, changes in design, poor site management \&supervision, poor workmanship and various other uncertain events. There is a need for the assessment of such delays due to rework in construction projects in order to estimate suitable buffers while planning for an upcoming project.

Identification and elimination of seven wastes (Ohno 1988) is one of the key aspects of lean production. The objective of the current study is to propose an alternate framework, which is built on lean concept for delay assessment in construction projects that can be used to model rework. Rework is considered to be one of the main reasons for construction delay. Two main causes for rework in construction projects are 'design changes' and 'non-conformances'. The proposed framework is based on Multiple Domain Matrix (MDM), a matrix based-tool that has been found to be suitable for delay analysis. This approach to model rework and assess delay would be helpful in the meaningful estimate of activity time buffers. Two construction case projects have been analysed using the proposed framework.

\section{LITERATURE REVIEW}

This section provides an account of existing literature on delays \& rework in construction, design change, non-conformance, waste, buffer and production planning \& control systems.

The construction delays are broadly classified in four major groups: compensable delay(delay caused by the owner), non-excusable delay (delay caused by the contractor), excusable delay (delay caused by any third party or act of god) and delays that can occur concurrently (Kraiem and Diekmann 1989). One common reason for any of the above delays is 'rework'. These reworks are non-value adding events and cause time waste in construction process. So, identification and elimination of causes leading to rework is crucial for successful project delivery.

Design change is one of the causes of rework, which leads to delay. Design change can happen in any stage of the project. The impact of design change is very high during the execution phase. According to Behzadand Sheryl(2012), design changes may be in the form of addition, deletion or modification to the scope of the project. Change attributes have been classified according to geometry (shape, dimension), position (coordinates, orientation) and specification (materials). Qi Hao (2008) reported that $30 \%$ of the clients are dissatisfied with the performance of the contractor as the contractors have failed in maintaining the quoted price, committed time, resolving defects and giving the good quality work. The root cause of the dissatisfaction was found to be the change orders' in the project.

Deviation from the quality requirements or the contractual terms is another common reason for rework and it is known as non-conformance. The Non-conformance reports (NCR) are issued by the clients or client representatives to the contractors for their substandard quality of work. Generally, the contractors are responsible for rectifying the work (rework) and getting the work certified from the client. These rectification works 
can delay the main activity and can halt the successive activities until the completion of the whole process. Gonzálezet al. (2014) have reported severe negative impact of noncompliances on the project time performance. Also, their research highlights the importance of identifying the reason for non compliance and managing them for better project management. Oyewobi et al. (2011) have reported that rework has a positive relationship with time overrun and cost overrun and have suggested to have quality assurance to reduce the non-conformance and in turn reduce the rework in a project.

Aziz and Hafez (2013) have proposed a pathway on how the lean thinking in construction can improve the performance. Along with its other principles lean talks about the reduction of waste (i.e. non-value adding activities). Rework can be classified as non-value adding activity in a construction project.It is evident that $30-35 \%$ of waste in construction is contributed by rework(Love et al. 2003).Ohno(1988) classified the waste in organisations as transportation, inventory, motion, waiting, over-production, overprocessing, and defects. Vianaet al. (2012) identified three different categories of waste in construction. They are (a) Construction material waste (physical waste),(b) Non valueadding activities (process waste) and(c) Specific sorts of waste (such as accidents and rework). According to Koskelaet al. (2013), making do waste is the lead waste in construction. Sarhanet al.(2014) used neo institutional theory to study the root cause for waste in construction organisations and proposed "institutional wastes" that is structural in nature. It is also recommended to shift attention from focussing merely on human behaviour and mistakes, to thinking systemically and structurally.

Buffers (in the form of material, work-in-progress, deliberate \& unintentional delays, and labour \& equipment) have been commonly used to safeguard production by absorbing the impact of uncertainties and variability that would normally disrupt production(Sakamoto et al. 2002). Also, it has been reinforced that providing some buffer would lead to superior performance in construction, as reported by various lean researchers. Ko (2006) proposed a Buffer Evaluation Model (BEM) using fuzzy logic to protect fabricators against the impact of demand variability. Application of lead-time buffer improves work flow and greater project profit(Srisuwanrat and Ioannou 2007). An investigation on the causes of time buffer revealed that project complexity, complexity of the trade task and quality of documents are the top three most frequent and severe causes (Russell et al. 2012).

Last Planner is a popular method for construction production control and improvement(Ballard and Howell 1998). The fourth principle among the basic five principles in this method recommends maintaining a buffer of tasks (Koskela 1999). Rational Commitment Model (RCM), complements Last Planner System in terms of forecasting capabilities to improve the reliability of planning commitments (Gonzalez et al. 2009). Multiple Domain Matrix (MDM) is a combination of Dependency Structure Matrix (DSM) and Domain Mapping Matrix (DMM), which can be used to map the relationship and dependencies among several entities(Mujumdar et al. 2014). DSM has been found to be very useful tool for project planning as it can plan the coupled activities which have both way dependencies whereas PERT and CPM tools can only model the sequential and parallel activities(Yassine 2004).The applicability of DSM has also eviden 
in modelling rework probabilities and scheduling of overlapping activities (Maheswari and Varghese 2005; Yassine et al. 2001).

There exists a need to investigate the factors leading to rework and its impact on delay that ultimately contribute to waste in construction. MDM has been found to be a promising tool to model the dependency among the activities. It has been attempted to model rework using MDM and subsequently estimate the time buffer.

\section{PROBLEM STATEMENT}

The following graphical representations (Figure 1 (a)\& 1(b)) demonstrate the problem statement.Figure1(a) shows how the 'change' in design can lead to rework and in turn delay. For example, suppose a change has been proposed to an activity during the execution phase while the activity has already been started. In that situation, the work has to be stopped immediately to incorporate the required change. It will lead to rework or replacement of the whole work. The particular activity is delayed as well as the dependent activities will also be delayed. Also, the process of decision-making, agreement and finalization of the change will lead to halting of the construction activity. Similarly, Figure1(b) shows how NCRs can play a vital role in time management of a project. It reveals the impact of NCR on time, from the instance deviations in quality are measured to the closure of an NCR. One of the major concerns regarding these events is that it can be repeated any time during the project. The effect of these can be accumulated in series or in parallel. So it is very much important for a project manager to be aware of such events and take precautionary action. It would be beneficial if it is possible to assess these delays that shall lead to creation of as-adjusted schedule that is more appropriate compared to as-planned or as-built schedules. This shall also eliminate the redundant buffer time added to activity durations as a common practice in order to account for delays.

\section{OBJECTIVES, SCOPE \& METHODOLOGY}

The objective of the study is to propose a lean framework for delay assessment in construction projects due to design change and non-conformance. The scope of the study is limited to time overruns only. MDM is proposed to identify and assess the relationships among the delay, design change and the non-conformance. To illustrate the design changes and the non-conformances, a transmission line project and a mall construction project have been chosen respectively. Semi-structured interviews have been conducted with the project team members to support the information gathered from the project documentation.

\section{PROPOSED SOLUTION FRAMEWORK FOR DELAY ASSESSMENT}

As represented in Figure 2, an intermediate step is proposed to assess the buffer duration

to make up for the delays due to rework. The current framework suggests appropriate 
buffer to account for the measured rework. This lean approach can ensure the timely delivery of the project.

In order to implement this framework, it is recommended to follow the below steps.

1. Analyse similar type of construction project(s) and identify all the possible reasons for the rework.

2. Formulate project specific change classification criteria and group them based on that criteria.

3. Identify the impact of each change and quantify them in terms of time delay or cost overrun.

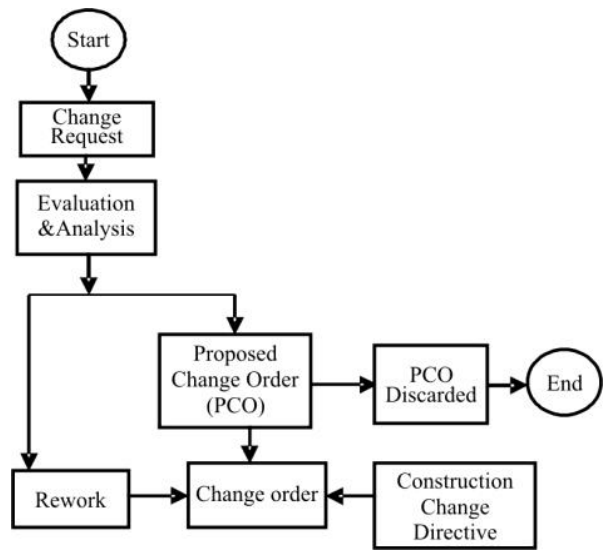

(a)

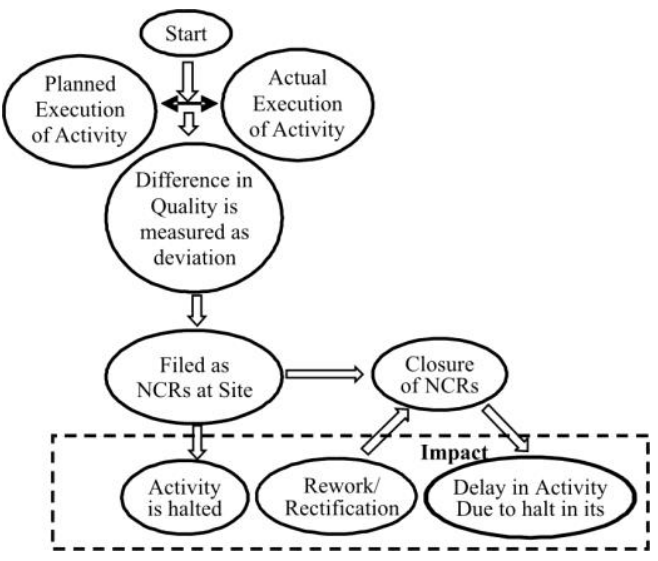

(b)

Figure 1: (a) Flow diagram for Design Changes and Delay (based on (González et al. 2014))

(b) Flow diagram for NCRs and Delay(based on (Kumar 2015))

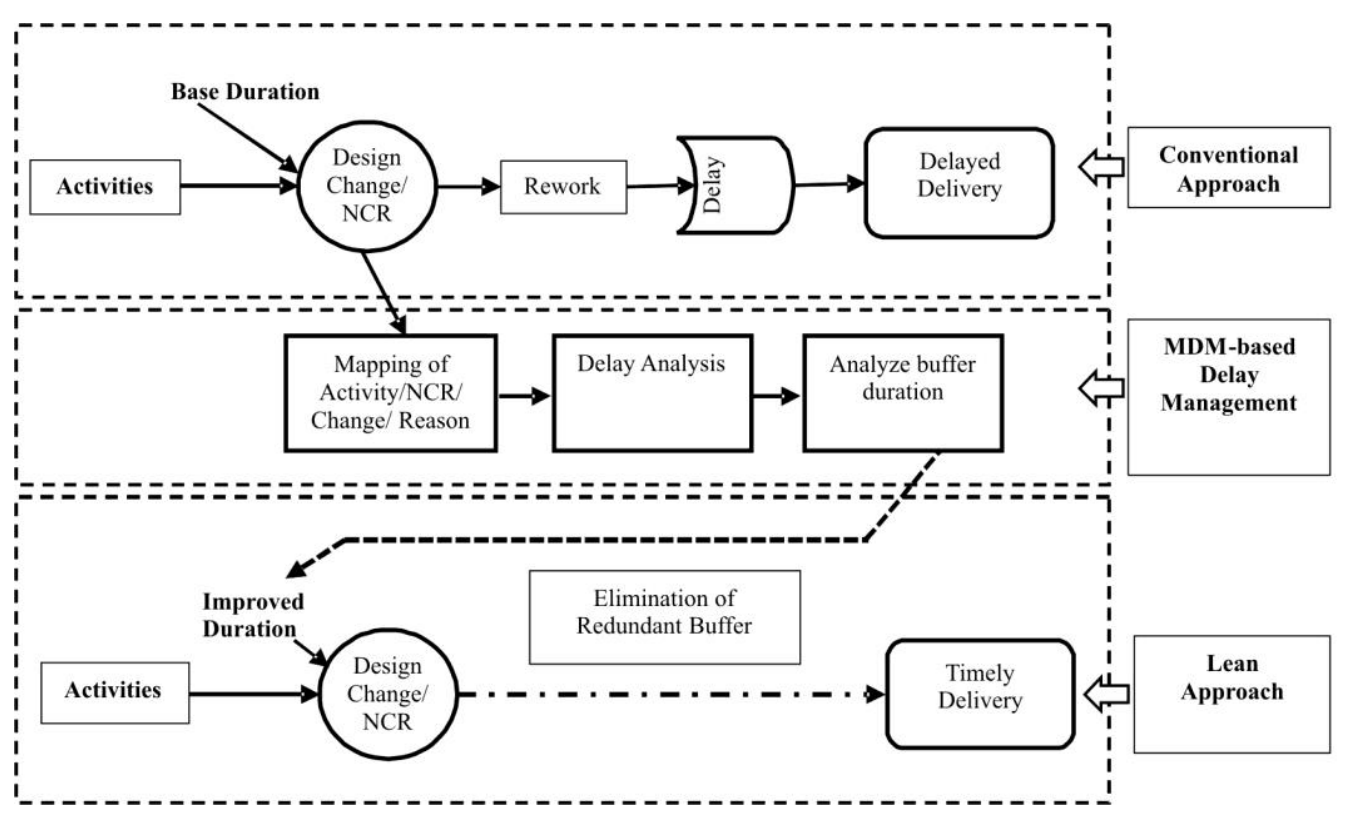

Figure 2: Proposed framework for delay management 
4. Correlate the changes and reason for changes based on their likelihood or probability. The likelihood and impact can be found out from the expert opinion or by analysing a number of similar projects.

5. Construct a multiple domain matrix (MDM) model for analysing the future impact as explained in the next section.

6. Apply the same model in any existing project for assessing and forecasting the probable impact expected from the change or rework.

\section{FORMATION OF MDM}

It is possible to form MDM to represent the relationship among the characteristics of the factors causing delay. For example, an MDM can be formed to represent the relationship among the anticipated changes, reasons for the changes and the impact of the change in the case of delay due to design change (Singhal 2017). Similarly, in the case of NCR, MDM is formed to represent the relationship among activities, NCRs and the impact(Maheswari et al. 2016). The work flow in the formation of MDM for this purpose of delay assessment is represented in Figure 3.

In the case of design change MDM (Figure 3(a)), the 1st quadrant of the matrix represents the Change DSM that shows the relationship among the changes. The fourth quadrant, Change Reason DSM represents the relationship among the reasons for the changes occurred in the project. The second quadrant represents the relationship among various changes and the reasons.

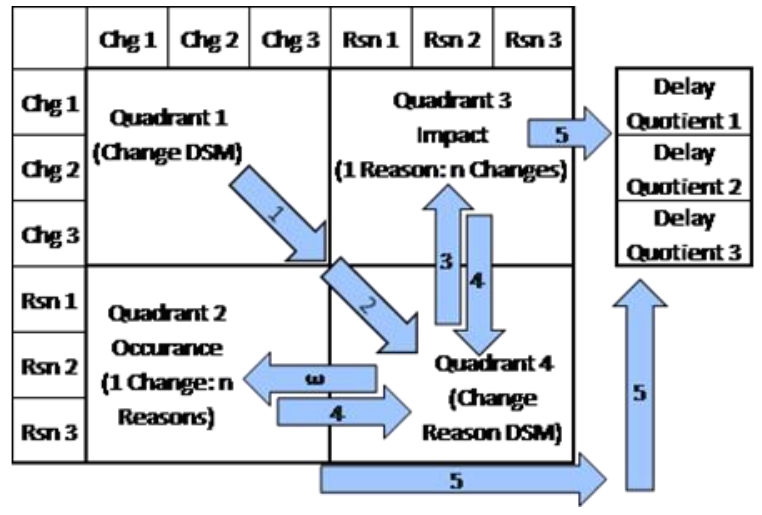

(a) Case A: Design Change

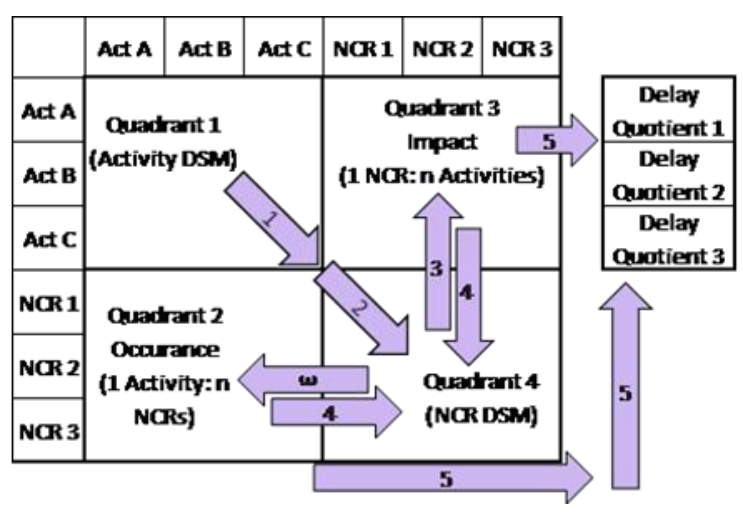

(b) Case B: Non-conformance

Figure 3: Workflow for MDM formation

The 3rd quadrant shows the impact of reasons on various changes happened in the project. The upper diagonal of the matrix represents the duration impact factor with respect to changes and the lower diagonal represents the duration impact factor with respect to reason for change (Singhal 2017). This leads to the estimation of delay quotients that is nothing but the estimate of time buffer. Similarly, MDM for the other factors causing delay such as NCR can be formed for further analysisas represented in Figure 3(b). 


\section{CASE STUDY APPLICATION \& RESULTS}

\section{CASE A: DESIGN CHANGE (TRANSMISSION LINE PROJECT)}

A transmission line project has been taken as the case study to investigate the impact of design change on routing of transmission line due to deviations in route. In this project, frequent deviation in the planned route has been encountered. The data collection was done to find out the different reasons for deviations in the transmission line route and they are listed in Table 1. The deviations implemented in route caused delay and cost overrun. An analysis of the project delay was done for $60 \mathrm{~km}$ of the stretch. It hasbeen found after analysis that angle of deviations were ranging from $0.5^{0}$ to $5^{0}$ due to reasons mentioned in Table 1. The buffer time has been estimated using the delay quotients arrived from the MDM as shown in Figure 4.

Table 1: Reasons for deviation in the proposed transmission line

\begin{tabular}{ll}
\hline Reasons for Deviations & Abbreviations \\
\hline To Avoid new construction on the route & ANC \\
To avoid existing trees and Garden on the route & AT \\
To Avoid fouling with high Tension Line & AHT \\
To avoid village coming on the proposed route & AV \\
Land Acquisition Problem & LAP \\
Decreasing Route Length in some locations & DRL \\
\hline
\end{tabular}

\begin{tabular}{|c|c|c|c|c|c|c|c|c|c|c|c|c|c|c|c|c|}
\hline & 0.5 & 1 & 1.5 & 2 & 2.5 & 3 & 3.5 & 4 & 4.5 & 5 & ANC & AT & AHT & AV & LAP & DRL \\
\hline 0.5 & 0.017 & & & & & & & & & & 0.033 & 0.026 & 0.005 & 0.003 & & \\
\hline 1 & & 0.031 & & & & & & & & & 0.032 & 0.020 & & & & \\
\hline 1.5 & & & 0.035 & & & & & & & & 0.000 & 0.013 & & 0.005 & & \\
\hline 2 & & & & 0.011 & & & & & & & & & 0.007 & 0.012 & & 0.004 \\
\hline 2.5 & & & & & 0.007 & & & & & & 0.009 & & 0.009 & 0.010 & & \\
\hline 3 & & & & & & 0.000 & & & & & & & 0.003 & 0.006 & 0.008 & 0.008 \\
\hline 3.5 & & & & & & & 0.004 & & & & 0.011 & & 0.002 & 0.005 & 0.003 & 0.008 \\
\hline 4 & & & & & & & & 0.003 & & & & & 0.005 & 0.004 & & \\
\hline 4.5 & & & & & & & & & -0.003 & & & & & & 0.007 & 0.008 \\
\hline 5 & & & & & & & & & & 0.001 & & & & & 0.012 & 0.023 \\
\hline ANC & 1.180 & 5.100 & 0.530 & & 1.240 & & 2.830 & & & & 0.245 & & & & & \\
\hline AT & 4.500 & 3.700 & 7.700 & & & & & & & & & 0.029 & & & & \\
\hline AHT & 2.500 & & & 4.900 & 1.000 & 0.320 & 0.630 & 0.730 & & & & & 0.062 & & & \\
\hline AV & 0.660 & & 1.150 & 1.800 & 2.200 & 0.970 & 0.900 & 0.670 & & & & & & 0.062 & & \\
\hline LAP & & & & & & 1.580 & 0.800 & & 0.870 & 0.870 & & & & & 0.045 & \\
\hline DRL & & & & -0.680 & & -2.270 & -1.800 & & -0.890 & -0.830 & & & & & & -0.061 \\
\hline
\end{tabular}

Figure 4: MDM for Case A 


\section{CASE B: NON-CONFORMANCE (MALL CONSTRUCTION PROJECT)}

Construction of a Mall has been taken as the case study to investigate the impact of nonconformance on project schedule. A pilot study was conducted for a period of three months in analysing the past NCR records of the project. The study was conducted to understand the occurrence, frequency, duration of the NCRs originating from various activities. It was found out that NCRs were repetitive in nature. A total of 350 closed NCRs from the project were analysed. Quality-related NCRs arising out of core civil construction activities such as reinforcement works, shuttering and concreting were considered for this study. The resultant MDM as represented in Figure5has been utilised to calculate the extended activity durations (with the help of delay quotients)and the updated activity durations have been estimated as shown in Table 2.

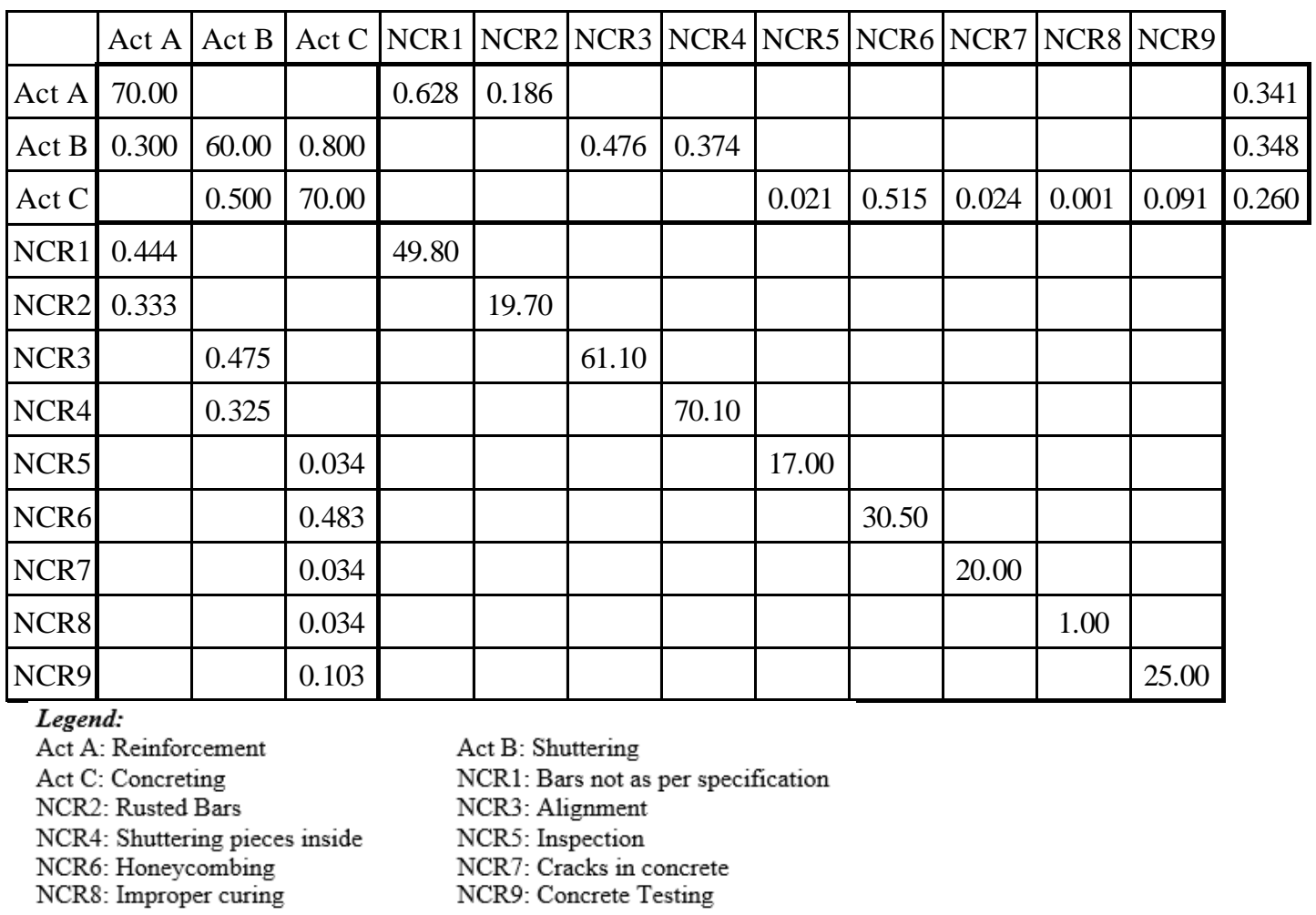

Figure 5: MDM for Case B

Table 2: Calculation of extended activity durations

\begin{tabular}{lllll}
\hline Activities & Duration & Delay quotient & Delay in activity & Extended duration \\
\hline Reinforcement & 70 days & 0.341 & 23.87 days & $93.87(\approx 94$ days $)$ \\
Shuttering & 60 days & 0.348 & 20.88 days & $80.88(\approx 81$ days $)$ \\
Concreting & 70 days & 0.260 & 18.2 days & $88.2(\approx 88$ days $)$ \\
\hline
\end{tabular}

From the above cases, the delay/time waste resulting from the rework has been calculated using the proposed framework. These models have been found to be effective in capturing the delay. In both the cases, the complexities are avoided by considering 
some basic assumptions such as NCRs are initiated before the scheduled completion of an activity. But for large and complex projects there is much scope for further studies.

\section{SUMMARY \&CONCLUSIONS}

The delay due to rework is a common issue in construction projects. The MDM models formed using the proposed framework for delay assessment have captured the relationship between change and its reasons as well as the dependencies among the activities and NCRs effectively. Further, the resultant MDM models have been used to estimate the delay in an objective way for a meaningful time buffer estimation. This method has been found to be very useful in the application of lean principles of eliminating/minimising the time waste by managing construction delay. The reduction of time delay by way of managing the rework probability can be a future scope for intensive research. The training of the model with more number of cases can provide precise forecast. However, the results from the proposed framework can help the project managers in assessing the possible time delay in the project arising from rework and take necessary corrective actions to manage them in future projects.

\section{REFERENCES}

Aziz, R. F., and Hafez, S. M. (2013). "Applying lean thinking in construction and performance improvement." Alexandria Engineering Journal, 679-695.

Ballard, G., and Howell, G. (1998). "Shielding Production: Essential Step in Production Control." Journal of Construction Engineering and Management, American Society of Civil Engineers, 124(1), 11-17.

Behzad, P. L., and Sheryl, S.-F. (2012). "Change Management with Building Information Models: A Case Study." ASCE, West Lafayette, Indiana, United States.

González, P., González, V., Molenaar, K., and Orozco, F. (2014). "Analysis of Causes of Delay and Time." Journal of Construction Engineering and Management, 140(1).

Gonzalez, V., Alarcon, L. F., Maturana, S., Mundaca, F., and Bustamante, J. A. (2009). "Rational Commitment Model: Improving Planning Reliability and Project Performance." 17th Annual Conference of the International Group for Lean Construction, 207-218.

Ko, C.-H. (2006). "Buffer Evaluation for Demand Variability Using Fuzzy Logic." 14th Annual Conference of the International Group for Lean Construction,255-264.

Koskela, L. (1999). "Management of Production in Construction: A Theoretical View." 7th Annual Conference of the International Group for Lean Construction, 241-252.

Koskela, L., Bølviken, T., and Rooke, J. (2013). "Which Are the Wastes of Construction?" 21th Annual Conference of the International Group for Lean Construction, 3-12.

Kraiem, Z. M., and Diekmann, J. E. (1989). "Concurrent Delays in Construction Projects." Journal of Construction Engineering and Management, 113(4).

Kumar, G. S. (2015). "Assessment of Non-Conformance report (NCR) based delays using Multiple Domain Matrix (MDM): Case study of Metro.” M. Tech Thesis, Indian Institute of Technology, Delhi, 2015, New Delhi, India.

Love, P., Irani, Z., and Edwards, D. (2003). "Learning to Reduce Rework in Projects: Analysis of Firm's Organisational Learning and Quality Practices." Project Management Journal, 13-25. 
Maheswari, J. U., Charlesraj, V. P. C., Kumar, G. S., and Padala, S. P. S. (2016). "A Study on Assessment of Non-conformances using Multiple Domain Matrix: A Case Study from Metro Projects.” Procedia Engineering, 145(2016), 622 - 629.

Maheswari, J. U., and Varghese, K. (2005). "Project Scheduling using Dependency Structure Matrix.” International Journal of Project Management, 223-230.

Mujumdar, P., Muraleedharan, P., and Maheswari, J. U. (2014). "Structured Methodology for applying Multiple Domain Matrices (MDM) to construction projects."Proceedings of $16^{\text {th }}$ International Dependency and Structure Modelling Conference, DSM 2014, Cambridge, UK, 299-308.

Make in India. (2018). "Make in India - Construction." Make in India, <http://www.makeinindia.com/web/mii/sector/construction>,Last visited 24May 2018.

MOSPI. (2017). Monthly summary for the Cabinet for the month of May 2017. Ministry of Statistics \& Programme Implementation, Government of India, New Delhi.

Ohno, T. (1988). Toyota Production System: Beyond large-scale production. Productivity Press, Portland, Oregon.

Oyewobi, L. O., Ibironke, O. T., Ganiyu, B. O., and Ola-Awo, A. W. (2011). "Evaluating rework cost- A study of selected building projects in Niger State, Nigeria." Journal of Geography and Regional Planning, 4(3), 147-151.

Qi Hao, Weiming Shen, Joseph Neelamkavil, and Russ Thomas. (2008). "Change Management in Construction Projects." CIB W78 International Conference on Information Technology in Construction, Santiago, Chile.

Russell, M. M., Howell, G., Hsiang, S. M., and Liu, M. (2012). "Causes of Time Buffer in Construction Project Task Durations." 20th Annual Conference of the International Group for Lean Construction.

Sakamoto, M., Horman, M. J., and Thomas, H. R. (2002). "A Study of the Relationship Between Buffers and Performance in Construction." 10th Annual Conference of the International Group for Lean Construction.

Sarhan, S., Pasquire, C., and King, A. (2014). "Institutional Waste within the Construction Industry - An Outline." 22nd Annual Conference of the International Group for Lean Construction, 895-906.

Singhal, R. (2017). "Delay Forecast in Construction Projects using Matrix based tools." M. Tech Thesis, Indian Institute of Technology, Delhi, 2015, New Delhi, India.

Srisuwanrat, C., and Ioannou, P. G. (2007). "The Investigation of Lead-Time Buffering Under Uncertainty Using Simulation and Cost Optimization." 15th Annual Conference of the International Group for Lean Construction, 580-589.

Viana, D. D., Formoso, C. T., and Kalsaas, B. T. (2012). "Waste in Construction: a Systematic Literature Review on Empirical Studies." 20th Annual Conference of the International Group for Lean Construction.

Yassine, A. (2004). "An introduction to modeling and analyzing complex product development processes using the design structure matrix (DSM) method." Urbana, 51(9), $1-17$.

Yassine, A. A., Whitney, D. E., and Zambito, T. (2001). "Assessment of rework probabilities for simulating product development processes using the design structure matrix (DSM)." Proceedings of DETC '01, Pittsburgh, Pennsylvania. 